Note

\title{
Surfactant Properties of Enzymatically Synthesized Monolauroyl Disaccharides
}

\author{
Tomoko TAKAHASHI, Takashi KoBAyashi and Shuji AdAchi ${ }^{*}$ \\ Division of Food Science and Biotechnology, Graduate School of Agriculture, Kyoto University, Sakyo-ku, Kyoto 606-8502, Japan
}

Received August 9, 2011; Accepted November 9, 2011

\begin{abstract}
Monolauroyl maltose, palatinose, trehalose and sucrose were synthesized by Candida antarctica lipasecatalyzed condensation in an organic solvent, and their surfactant properties were measured at $25^{\circ} \mathrm{C}$. The type of hydrophilic moiety of the lauroyl disaccharides did not significantly affect the critical micelle concentration, the surface tension at this concentration, residual area per molecule, free energy of micellization or micelle size, but produced different solubilization ability against octanoic acid.
\end{abstract}

Keywords: surface activity, nonionic surfactant, lipase, monolauroyl disaccharide

\section{Introduction}

The sucrose fatty acid ester is a nonionic surfactant and has been widely used in the food, cosmetic and pharmaceutical fields due to its biodegradability and biocompatibility (Baker et al., 2000). Fatty acid esters of other di-, monoand trisaccharides have also been shown to be surface active (Söderberg et al., 1995; Garofalakis et al., 2000; Kjellin et al., 2001; Douglas and Tao, 2002; Ferrer et al., 2002; Zhang et al., 2003; Chen et al., 2005; Chen et al., 2007; Piao et al., 2007; Sun et al., 2009). Recently, enzymatic synthesis in organic solvents has attracted attention as an alternative to conventional chemical synthesis of esters (Carrea and Riva, 2000). In particular, lipase from Candida antarctica preferentially acylates primary hydroxyl groups, and the lipase is used in the condensation of mono-, di- and trisaccharides with various fatty acids (Cao et al., 1999; Degn et al., 1999; Zhang et al., 2003; Soultani et al., 2003; Chen et al., 2005; Chen et al., 2007; Piao et al., 2007; Sun et al., 2009).

It has been reported that the surface activity of the sugar fatty acid esters is affected by the type of sugar head group, the length of the acyl chain and the composition of the esters (Garofalakis et al., 2000; Ferrer et al., 2002; Soultani et al., 2003; Chen et al., 2007; Imura et al., 2010; Schiefelbein et $a l ., 2010)$. The effect of the sugar head group on the surfactant properties has usually been investigated for the esters of saccharides having different molecular masses, such as the mono-, di- and trisaccharides. The difference in the molecu-

*To whom correspondence should be addressed.

E-mail: adachi@kais.kyoto-u.ac.jp lar mass of the hydrophilic moiety of the esters produces a difference in their hydrophilic-lipophilic balance (HLB) and hence affects their surfactant properties. Furthermore, most of the reports have dealt with only the surface tension and the critical micelle concentration (CMC), while the micelle size or solubilizing capacity has been scarcely investigated. Solubilized solutions are colorless, transparent and thermodynamically stable. Solubilization also enables the suppression of lipid oxidation and flavor deterioration, and improves flavor by lipophilic aromatic compounds. Therefore, solubilization is a useful technique in food. However, the amount of solubilized substance is limited because solubilized particle sizes are usually smaller than $10 \mathrm{~nm}$. In this context, evaluation of the solubilizing capacity of surfactants and of the factors affecting solubilization are important.

In this study, we synthesized the lauroyl esters of several disaccharides using Candida antarctica lipase in an organic solvent, and examined whether the surfactant properties of these esters, which have the same HLB number, were affected by the disaccharide type. The disaccharides used were maltose, palatinose, trehalose and sucrose. The surface tensions were measured at $25^{\circ} \mathrm{C}$ to estimate the $\mathrm{CMC}$ and the surface tensions at the $\mathrm{CMC}$, which are general surfactant properties. The micelle size and solubilizing capacity of these esters against octanoic acid were also measured.

\section{Materials and Methods}

Materials Immobilized lipase from Candida antarctica (Chirazyme ${ }^{\circledR}$ L-2 c.-f. C-2) was purchased from Roche Molecular Biochemicals (Mannheim, Germany). Maltose 
monohydrate and trehalose dihydrate were purchased from Hayashibara, Okayama, Japan. Lauric acid, palatinose monohydrate, and sucrose were purchased from Wako Pure Chemical Industries, Osaka, Japan. All other chemicals were purchased from Wako Pure Chemical Industries.

Enzymatic synthesis and purification of monolauroyl disaccharides The monolauroyl esters of maltose, palatinose, trehalose and sucrose were synthesized according to our previous procedures (Piao et al., 2007) with some modifications. The disaccharide $(50 \mathrm{mmol})$ and lauric acid $(100$ mmol) were weighed into a glass bottle, then dissolved or suspended in a mixture of tert-butyl alcohol and pyridine ( $8 / 2$ by vol., $500 \mathrm{~mL})$. The immobilized lipase $(5 \mathrm{~g})$ was put into a nylon-mesh bag and added to the bottle. The bottle was tightly screw-capped and immersed in a water bath at $60^{\circ} \mathrm{C}$ with shaking at $c a .120$ strokes/min to start the condensation reaction. After $48 \mathrm{~h}$, the reaction mixture was sampled and the formation of the lauroyl disaccharides using HPLC was evaluated. The HPLC was equipped with an LC-10AD pump (Shimadzu, Kyoto, Japan), a 5C18-AR-II column (4.6 mm ID $\times 150 \mathrm{~mm}$, Nacalai Tesque, Kyoto) and an SPD-10AV UV detector (Shimadzu). The eluent was a mixture of isopropyl alcohol, acetonitrile and water (33/30/37 by vol.) at a flow rate of $0.8 \mathrm{~mL} / \mathrm{min}$.

The reaction mixture was filtered through No. 2 filter paper (Toyo Roshi, Tokyo, Japan) to remove any undissolved disaccharide. The filtrate was rotary-evaporated under reduced pressure to remove the solvent. Hexane was added to the remainder to dissolve lauric acid and the hexane phase was removed by decantation. Acetone was then added to the remainder to dissolve the esters and the acetone phase was obtained by filtration. The acetone solution was then rotaryevaporated under reduced pressure to recover the esters. The condensation products were confirmed to be the desired ones based on their ${ }^{1} \mathrm{H}$ NMR spectra. The ${ }^{1} \mathrm{H}$ NMR spectra of the products were as follows. Monolauroyltrehalose: $\delta$ (ppm, $\left.500 \mathrm{MHz}, \mathrm{CD}_{3} \mathrm{OD}\right) 0.90(3 \mathrm{H}, \mathrm{t}, J=7.1 \mathrm{~Hz}), 1.29(16 \mathrm{H}, \mathrm{m})$, $1.61(2 \mathrm{H}, \mathrm{m}), 2.34(2 \mathrm{H}, \mathrm{t}, J=7.4 \mathrm{~Hz}), 3.35(2 \mathrm{H}, \mathrm{m}), 3.47(2 \mathrm{H}$, $\mathrm{m}), 3.67(1 \mathrm{H}, \mathrm{m}), 3.74-3.86(4 \mathrm{H}, \mathrm{m}), 4.01(1 \mathrm{H}, \mathrm{m}), 4.20$ $(1 \mathrm{H}, \mathrm{m}), 4.36(1 \mathrm{H}, \mathrm{m}), 5.08(2 \mathrm{H}, \mathrm{m})$. Monolauroylsucrose: $\delta$ (ppm, $\left.500 \mathrm{MHz}, \mathrm{CD}_{3} \mathrm{OD}\right) 0.90(3 \mathrm{H}, \mathrm{t}, J=7.1 \mathrm{~Hz}), 1.29(16 \mathrm{H}$, $\mathrm{m}), 1.61(2 \mathrm{H}, \mathrm{m}), 2.35(2 \mathrm{H}, \mathrm{m}), 3.25(1 \mathrm{H}, \mathrm{m}), 3.40(1 \mathrm{H}, \mathrm{m})$, $3.56-3.84(5 \mathrm{H}, \mathrm{m}), 3.91-4.20(4 \mathrm{H}, \mathrm{m}), 4.30-4.55(2 \mathrm{H}$, $\mathrm{m}), 5.38(1 \mathrm{H}, \mathrm{m})$. Monolauroylmaltose: $\delta(\mathrm{ppm}, 500 \mathrm{MHz}$, $\left.\mathrm{CD}_{3} \mathrm{OD}\right) 0.90(3 \mathrm{H}, \mathrm{t}, J=7.1 \mathrm{~Hz}), 1.29(16 \mathrm{H}, \mathrm{m}), 1.61(2 \mathrm{H}$, m), $2.37(2 \mathrm{H}, \mathrm{t}, J=7.4 \mathrm{~Hz}), 3.26(1 \mathrm{H}, \mathrm{m}), 3.38-3.50(3 \mathrm{H}$, $\mathrm{m}), 3.63(1 \mathrm{H}, \mathrm{m}), 3.75-3.92(5 \mathrm{H}, \mathrm{m}), 4.17(1 \mathrm{H}, \mathrm{m}), 4.39(1 \mathrm{H}$, $\mathrm{m}), 5.10(2 \mathrm{H}, \mathrm{m})$. Monolauroylpalatinose: $\delta(\mathrm{ppm}, 500 \mathrm{MHz}$, $\left.\mathrm{CD}_{3} \mathrm{OD}\right) 0.90(3 \mathrm{H}, \mathrm{t}, J=7.1 \mathrm{~Hz}), 1.29(16 \mathrm{H}, \mathrm{m}), 1.60(2 \mathrm{H}, \mathrm{m})$, $2.34(2 \mathrm{H}, \mathrm{t}, J=7.5 \mathrm{~Hz}), 3.31(1 \mathrm{H}, \mathrm{m}), 3.40(1 \mathrm{H}, \mathrm{m}), 3.47(1 \mathrm{H}$, m), $3.55-3.72(3 \mathrm{H}, \mathrm{m}), 3.78-3.92(3 \mathrm{H}, \mathrm{m}), 3.96(1 \mathrm{H}, \mathrm{m})$, $4.06(1 \mathrm{H}, \mathrm{m}), 4.14(1 \mathrm{H}, \mathrm{m}), 4.21(1 \mathrm{H}, \mathrm{m}), 4.37(1 \mathrm{H}, \mathrm{m})$.

Surface tension Each monolauroyl disaccharide was dissolved in distilled water at various concentrations. The surface tensions of the solutions were measured by the drop weight method at $25^{\circ} \mathrm{C}$. The measurement was conducted in triplicate under specific conditions, and the values were averaged.

Micelle size The size distribution of the micelles in a monolauroyl disaccharide solution was measured at $25^{\circ} \mathrm{C}$ using a DLS-7000 dynamic light scattering spectrophotometer (Otsuka Electronics, Osaka, Japan) to estimate the median diameter based on the weight fraction. The diameter was measured at various concentrations of each monolauroyl disaccharide.

Solubilizing capacity Octanoic acid was chosen as the solubilized compound. A monolauroyl disaccharide solution dissolved in distilled water at various concentrations (5 $\mathrm{mL}$ each) was added to the vials. The appropriate amount of octanoic acid was then added to the vials. The vials were immersed in a water bath at $25^{\circ} \mathrm{C}$ with shaking at $c a .160$ strokes/min. After achieving equilibrium, the absorbance of the solutions was measured using a UV-1200 UV-VIS spectrophotometer (Shimadzu) at $500 \mathrm{~nm}$.

\section{Results and Discussion}

Surface activities of monolauroyl disaccharides Figure 1 shows the surface tension curves of the monolauroyl disaccharides at $25^{\circ} \mathrm{C}$. The $\mathrm{CMC}$ was estimated from the intersection of the two lines for each ester. The surface tension at the $\mathrm{CMC}, \gamma \mathrm{CMC}$, was also determined from the intersection. The surface excess, $\Gamma$, was evaluated from the slope of the line drawn at the low concentrations according to the Gibbs equation:

$$
\frac{d \gamma}{d \log C}=-2.30 \Gamma R T
$$

where $\gamma$ is the surface tension, $C$ is the concentration, $R$ is the gas constant and $T$ is the absolute temperature. The residual area per molecule, $a$, was calculated from Eq. (2).

$$
a=1 /\left(N_{\mathrm{A}} \Gamma\right)
$$

where $N_{\mathrm{A}}$ is Avogadro's number. The free energy of micellization, $\Delta G_{\mathrm{m}}$, is given by Eq. (3).

$$
\Delta G_{\mathrm{m}}=R T \ln \mathrm{CMC}
$$

The surfactant properties of the monolauroyl maltose, palatinose, trehalose and sucrose at $25^{\circ} \mathrm{C}$ are summarized in Table 1. It was reported that the $\mathrm{CMC}$ value of the monolauroyl trehalose was $0.56 \mathrm{mmol} / \mathrm{L}$ at $30^{\circ} \mathrm{C}$ (Chen et al., 2007), those of the monolauroyl maltose were $0.24 \mathrm{mmol} / \mathrm{L}$ at $25^{\circ} \mathrm{C}$ 


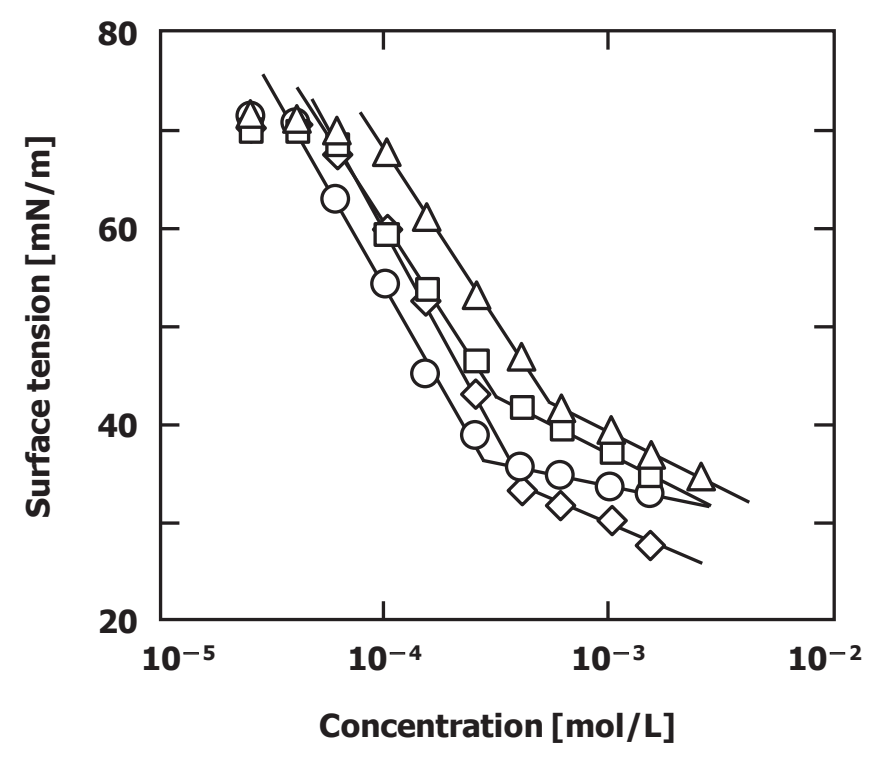

Fig. 1. Surface tension curves of monolauroyl maltose $(\bigcirc)$, palatinose $(\diamond)$, trehalose $(\triangle)$ and sucrose $(\square)$ at $25^{\circ} \mathrm{C}$.

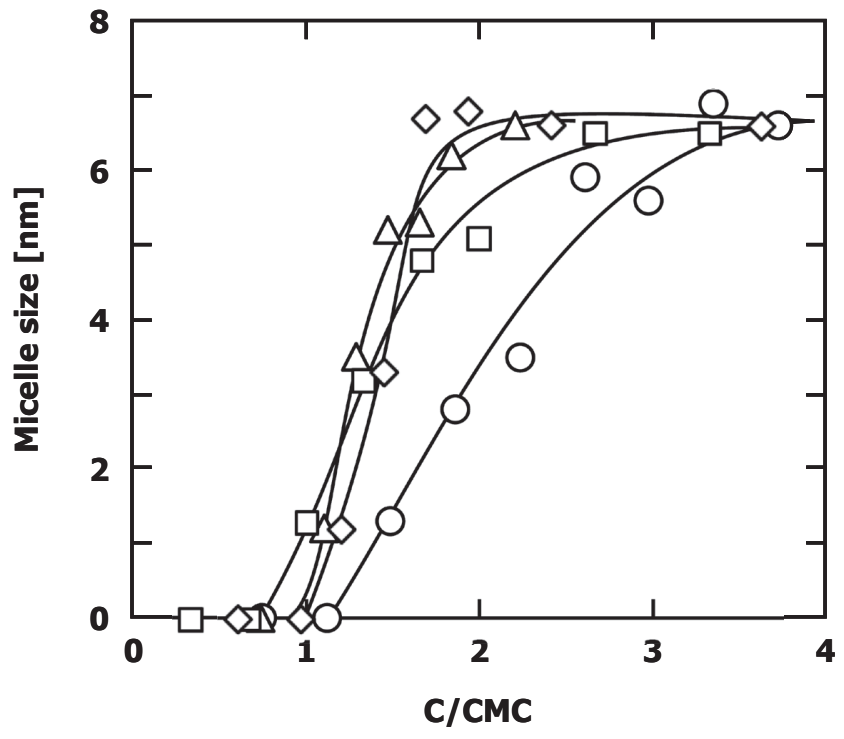

Fig. 2. Concentration dependence of the micelle size of monolauroyl maltose, palatinose, trehalose and sucrose at $25^{\circ} \mathrm{C}$. The symbols are the same as in Fig. 1.

Table 1. Surface activities of monolauroyl disaccharides at $25^{\circ} \mathrm{C}$.

\begin{tabular}{lccccc}
\hline Saccharide & $\mathrm{CMC}[\mathrm{mmol} / \mathrm{L}]$ & $\gamma \mathrm{CMC}[\mathrm{mN} / \mathrm{m}]$ & $\Gamma \times 10^{6}\left[\mathrm{~mol} / \mathrm{m}^{2}\right]$ & $a\left[\mathrm{~nm}^{2}\right]$ & $\Delta \mathrm{Gm}[\mathrm{kJ} / \mathrm{mol}]$ \\
\hline Maltose & 0.27 & 36.3 & 7.15 & 0.23 & -20.3 \\
Palatinose & 0.42 & 33.5 & 7.30 & 0.23 & -19.3 \\
Trehalose & 0.54 & 42.3 & 6.11 & 0.27 & -18.7 \\
Sucrose & 0.31 & 43.0 & 6.20 & 0.27 & -20.0 \\
\hline
\end{tabular}

(Ferrer et al., 2002) and $0.33 \mathrm{mmol} / \mathrm{L}$ at $22^{\circ} \mathrm{C}$ (Kjellin et al., 2001), and those of the monolauroyl sucrose were 0.45 $\mathrm{mmol} / \mathrm{L}$ at $20^{\circ} \mathrm{C}$ (Söderberg et al., 1995), $0.25 \mathrm{mmol} / \mathrm{L}$ at $25^{\circ} \mathrm{C}$ (Ferrer et al., 2002), and $0.21 \mathrm{mmol} / \mathrm{L}$ at $32^{\circ} \mathrm{C}$ (Garofalakis et al., 2000). The CMC values of the monolauroyl disaccharides synthesized in this study were almost the same as the reported ones. There were no significant differences in the CMC, $\Gamma, a$ and $\Delta G_{\mathrm{m}}$ among the four monolauroyl disaccharides tested here, and a similar tendency has also been reported for the monomyristoyl disaccharides (Piao et al., 2007). As shown in Table 1, the $\gamma \mathrm{CMC}$ value depended slightly on the type of disaccharide. These results indicated that the type of hydrophilic moiety of the acyl disaccharides does not significantly affect their surfactant properties.

Micelle size of monolauroyl disaccharides The micelle sizes of the monolauroyl disaccharides were measured at various concentrations and at $25^{\circ} \mathrm{C}$ (Fig. 2). Because each monolauroyl disaccharide had a slightly different $\mathrm{CMC}$ value, the concentrations were normalized by the $\mathrm{CMC}$ value in the figure. When the concentration was beyond the $\mathrm{CMC}$, the micelle size increased with increasing concentration. The micelle size of the monolauroyl maltose increased more gradually compared with those of other monolauroyl disaccharides. This was ascribed to the lower CMC value of the monolauroyl maltose. For all the monolauroyl disaccharides, the micelle size became $c a .7 \mathrm{~nm}$ at concentrations 2 to 3 times higher than their $\mathrm{CMC}$ values, i.e., 0.7 to $1.0 \mathrm{mmol} / \mathrm{L}$, and no further increase in the micelle size was observed at higher concentrations. Thus, the micelle size was also not affected by the type of hydrophilic moiety of the lauroyl disaccharides.

Solubilization ability of monolauroyl disaccharides The solubilizing capacity of each monolauroyl disaccharide was assessed by measuring the amount of octanoic acid solubilized into the micelles at $25^{\circ} \mathrm{C}$. Figure 3 shows the absorbance at $500 \mathrm{~nm}$ of the monolauroyl palatinose solutions to which various amounts of octanoic acid had been added. The absorbance abruptly increased when the amount was beyond a certain level. The maximum solubilizing capacity was estimated from the intersection of the two lines drawn at the low and high concentrations.

Figure 4 shows the concentration of octanoic acid solubilized into the micelle at the various surfactant (monolauroyl disaccharide) concentrations for the four monolauroyl di- 


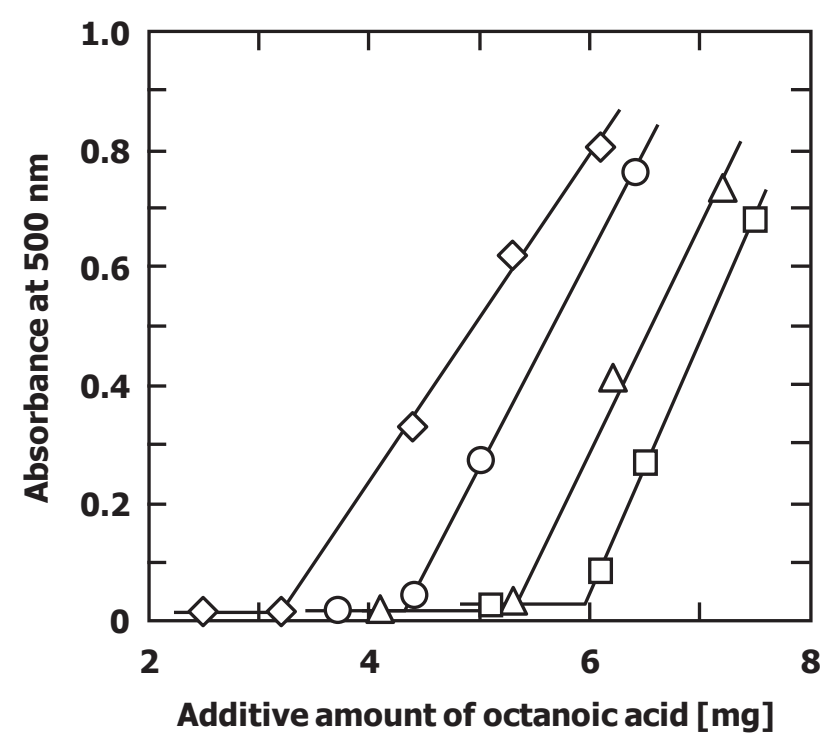

Fig. 3. Examples of octanoic acid solubilization of monolauroyl palatinose at $25^{\circ} \mathrm{C}$. The monolauroyl palatinose concentration was $0.1(\diamond), 0.2(\bigcirc), 0.3(\triangle)$ and $0.4 \mathrm{mmol} / \mathrm{L}(\square)$.

saccharides. The slope of the line denotes the solubilization ability of the surfactant, with a higher slope indicating higher ability. The slopes of the monolauroyl maltose, palatinose, trehalose and sucrose were $0.88,1.2,2.0$ and 2.0, respectively. The monolauroyl trehalose and sucrose had the highest ability, followed by monolauroyl palatinose and maltose. It is generally recognized that the factors affecting the ability are the acyl chain length, micelle size, ionicity of the surfactant, and temperature (Nagarajan, 1996). The esters tested in this study were all nonionic, with the same acyl chain and almost the same micelle size. The measurements were also conducted at the same temperature. Therefore, it is suggested that the hydrophilic moiety type affects the solubilization ability even if the molecular mass of the moiety is the same. The reason for the different ability is unexplained, but it may be ascribed to the weak surface activity of octanoic acid.

Acknowledgements This study was financially supported by the Food Nanotechnology Project by the Ministry of Agriculture, Forestry, and Fisheries, Japan.

\section{References}

Baker, I.J. A., Matthews, B., Suares, H., Krodkiewska, I., Furlong, D.N., Grieser F. and Drummond, C.J. (2000). Sugar fatty acid ester surfactants: structure and ultimate aerobic biodegradability. J. Surf. Deterg., 3, 1-11.

Cao, L., Bornscheuer, U.T. and Schmid, R.D. (1999). Lipasecatalyzed solid-phase synthesis of sugar esters. Influence of immobilization on productivity and stability of the enzyme. J. Mol. Catal. B: Enzymatic, 6, 279-285.



Fig. 4. Octanoic acid solubilization ability of monolauroyl maltose, palatinose, trehalose and sucrose at $25^{\circ} \mathrm{C}$. The symbols are the same as in Fig. 1.

Carrea, G. and Riva, S. (2000). Properties and synthetic application of enzymes in organic solvents. Angew. Chem. Intl. Ed., 39, 2226-2254.

Chen, J., Kimura, Y. and Adachi, S. (2005). Synthesis of linoleoyl disaccharides through lipase-catalyzed condensation and their surface activities. J. Biosci. Bioeng., 100, 274-279.

Chen, J., Kimura, Y. and Adachi, S. (2007). Surface activities of monoacyl trehaloses in aqueous solution. LWT-Food Sci. Technol., 40, 412-417.

Degn, P., Pedersen, L.H., Duus, J.Ø. and Zimmermann, W. (1999). Lipase-catalysed synthesis of glucose fatty acid esters in tertbutanol. Biotechnol. Lett., 21, 275-280.

Douglas, K.A. and Tao, B.Y. (2002). Synthesis and characterization of maltose fatty acid monoesters as biosurfactants. J. Surf. Deterg., 5, 245-255.

Ferrer, M., Comelles, F., Plou, F.J., Cruces, M.A., Fuentes, G., Parra, J.L. and Ballesteros, A. (2002). Comparative surface activities of di- and trisaccharide fatty acid esters. Langmuir, 18, 667-673.

Garofalakis, G., Murray, B.S. and Sarney, D.B. (2000). Surface activity and critical aggregation concentration of pure sugar esters with different sugar headgroups. J. Colloid Interf. Sci., 229, 391398.

Imura, T., Masuda, Y., Minamikawa, H., Fukuoka, T., Konishi, M., Morita, T., Sakai, H., Abe, M. and Kitamoto, D. (2010). Enzymatic conversion of diacetylated sophoroselipid into acetylated glucoselipid: Surface-active properties of novel bolaform biosurfactants. J. Oleo Sci., 59, 495-501.

Kjellin, U.R.M., Claesson, P.M. and Vulfson, E.N. (2001). Studies of $\mathrm{N}$-dodecyllactobionamide, maltose 6'-O-dodecanoate, and octyl- $\beta$-glucoside with surface tension, surface force and wetting 
techniques. Langmuir, 17, 1941-1949.

Nagarajan, R. (1996). Solubilization in aqueous solutions of amphiphiles. Cur. Opin. Colloid Interf. Sci., 1, 391-401.

Piao, J., Takase, K. and Adachi, S. (2007). Enzymatic synthesis of myristoyl disaccharides and their surface activity. J. Sci. Food Agric., 87, 1743-1747.

Schiefelbein, L., Keller, M., Weissmann, F., Luber, M., Bracher, F. and Frieß, W. (2010). Synthesis, characterization and assessment of suitability of trehalose fatty acid esters as alternatives for polysorbates in protein formulation. Eur. J. Pharm. Biopharm., 76, 342-350.

Söderberg, I., Drummond, C.J., Furlong, D.N., Godkin, S. and Matthews, B. (1995). Non-ionic sugar-based surfactants: self assembly and air/water interfacial activity. Colloid. Surf. A: Physi- cochem. Eng. Aspects, 102, 91-97.

Soultani, S., Ognier, S., Engasser, J.M. and Ghoul, M. (2003). Comparative study of some surface active properties of fructose esters and commercial sucrose esters. Colloid. Surf. A: Physicochem. Eng. Aspects, 227, 35-44.

Sun, Y., Xia, W., Tang, X., He, Z. and Chen, J. (2009). Effects of fatty acid chain length and degree of unsaturation on the surface activities of monoacyl trehaloses. Front. Chem. Eng. China, 3, 407-412.

Zhang, X., Kobayashi, T., Watanabe, Y., Fujii, T., Adachi, S., Nakanishi, K. and Matsuno, R. (2003). Lipase-catalyzed synthesis of monolauroyl maltose through condensation of maltose and lauric acid. Food Sci. Technol. Res., 9, 110-113. 